\title{
Efficacy of Endovascular Therapy for Direct Occlusion of Intracranial Aneurysms
}

\author{
Tamrakar K,' Karki B, ${ }^{2}$ Duan C- Z,' Li X-F,'Zhang X' \\ 'Department of Neurosurgery, Zhujiang Hospital, ${ }^{2}$ Department of Radiology, Nanfang Hospital, Southern Medical \\ University (First Military Medical University)
}

\section{ABSTRACT}

Introduction: Our purpose was to evaluate the effectiveness of endovascular therapy using detachable coils and balloons for the direct occlusion of intracranial aneurysms.

Methods: We retrospectively reviewed 563 patients undergoing digital subtraction angiography from January 2007 to July 2009. Two hundred and fifty patients with 323 embolized intracranial aneurysms were studied.

Results: Among 250 patients, $66 \%$ were female and $34 \%$ male, the age ranging from 19 - 83 years (mean $50.66 \pm 12.92$ ). One hundred and seventy-seven had a single aneurysm while 73 showed multiple aneurysms. Seventeen (9.6 \%) had giant aneurysms. Three hundred and eleven aneurysms were treated using detachable coils, and 12 giant aneurysms were embolized by detachable balloons for the parent vessel occlusion. Of 323 aneurysms treated via the endovascular approach, total occlusion was seen in $93 \%$ of the aneurysms, near total occlusion in $5.2 \%$ and incomplete embolization in $1.5 \%$. Among patients presenting with sub-arachnoid hemorrhage, 62 improved to the Glasgow outcome score (GOS) of 5, 93 improved to GOS 4, 14 improved to GOS 3, 10 improved to GOS 2 at the time of discharge and 5 patients died. Angiographic follow-up was scheduled between 6 - 12 months post-embolization. The aneurysm recurred in $1.2 \%$ and were re-embolized using additional coils. Statistically, Hunt and Hess Grade and GOS indicated clinical significance $(\mathrm{P}<0.05)$. The patients, gender, clinical presentation and aneurysmal location did not show statistical significance $(\mathrm{P}>0.05)$.

Conclusions: Hunt and Hess VI and V are considered as poor clinical gradings in aneurysmal $\mathrm{SAH}$. However, endovascular treatment has been established as an effective method to obliterate intracranial aneurysms allowing subsequent decrease in mortality and morbidity.

Keywords: detachable coils, detachable balloons, endovascular therapy, intracranial aneurysms

\section{INTRODUCTION}

Endovascular therapy has been an increasingly used method for the obliteration of intracranial aneurysms since the early 1970s when Fedor A. Serbinenko succeeded in experimenting with latex balloons and Guido Guglielmi perfected the technique of coil embolization in $1991.1,2$ With the successful results achieved in shortterm clinical and angiographic follow-ups, this technique has proven to be an alternative therapy to surgical clipping. ${ }^{2,3}$ Due to the complex anatomical structures, perforating vessels and cranial nerves, surgical access to those aneurysms located in difficult locations are

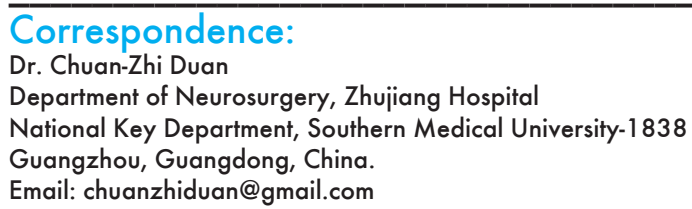


difficult to trap and clip, carrying a high risk of damage to surrounding brain parenchyma. Because of the small operative field, a patient presenting with a ruptured aneurysm and subarachnoid hemorrhage (SAH) in the CT scan poses a particularly intimidating surgical challenge. The new advancement made in the materials and methods used in interventionals neurosurgery have further refined the endovascular technology for a more successful treatment of intracranial aneurysms.

\section{METHODS}

Patients: We retrospectively collected the data of patients who underwent cerebral angiography for detection of cerebral aneurysms from January 2007 to July 2009. Clinical and angiographic records were obtained from the neurosurgical database of our hospital. Surgically-clipped aneurysms were excluded from this study. All the included data were reviewed and analyzed by two neurosurgeons having more than 15 years of experience in interventional neurosurgery.

Clinical and angiographic evaluation method: The initial clinical presentations of every patient were recorded. Patients presenting with $\mathrm{SAH}$ were categorized according to the Hunt and Hess grade classification. Consent was obtained from patients or his/her family members for 4-vessel angiography. Digital subtraction angiogram (DSA) was performed under AXIOM Artis, C arm unit (Siemens Medical System, Germany). In most of the cases, the study of the anatomical configuration of the aneurysms and the planned endovascular treatment were scheduled in same angiographic setting and the procedure was performed between Day 1 to Day 5 of admission. All procedures were performed by two endovascular neurosurgeons in the interventional therapy center of our hospital. Complications following therapy were detailed. The angiographic evaluation of each factor was stratified as total occlusion $(95$ - $100 \%$ embolization), near total occlusion (90 - 95 $\%$ embolization) and incomplete occlusion (< $90 \%$ embolization). The glasgow outcome scoring (GOS) method was applied to assess post embolization recovery at the time of discharge. Clinical follow-up were scheduled at 1, 3, 6 and 12 months, and angiographic follow up at $6-12$ months of post-embolization.

Statistical analysis: The patients' gender, clinical presentation, aneurysmal location, Hunt and Hess grade and GOS were analyzed statistically. Statistical analysis was performed with SPSS version 13.0 software package (Chicago, USA). Data were analyzed using the Nonparametric K-related test, and a P-value of $<0.05$ was considered to be statistically significant.

Coil embolization technique: After obtaining consent from the patients or family members, conventional angiography was done via the femoral access under sedation and local anesthesia. In patients with an illdefined aneurysmal neck detected in conventional angiography, 3D rotational DSA was performed for optimal visualization. Various microcatheters of Excel-10 series (Boston Scientific), Echelon series (eV3, Micro Therapeutics) and microguidewires like Transcend series (Boston Scientific) or Silver Speed-10 series (eV3) were navigated to locate the target point in the road map. After wedging the microcatheter tip in the aneurysmal sac, subsequent platinum detachable coils (GDCs; Boston Scientific) were deployed till the aneurysms were densely packed angiographically. 5000 IU heparin was intravenously administered to every patient after deploying the first coil followed by $1000 \mathrm{IU}$ every hour, maintaining the activated clotting time level of $2-2.5$ times the baseline value until the whole procedure was completed. In cases with intraprocedural bleeding, rapid completion of coil packing and immediate reversal of heparin with protamine sulfate at the dose of $10 \mathrm{mg}$ per $1000 \mathrm{IU}$ of heparin was intravenously given. CT head was immediately done, and in cases of mounting intracranial hemorrhage $(\mathrm{ICH})$, external ventricular drainage or evacuation of hematoma was performed immediately. All patients were then transferred to the neuro-intensive care unit for at least 24 hours of observation. After being clinically stable, the patients were discharged after a 4 - 21 days of post-embolization period.

\section{RESULTS}

Our search yielded 250 patients with 323 intracranial aneurysms among 563 DSA, who had been subsequently treated by endovascular therapy using detachable coils and balloons. Sixty six percent were female and $34 \%$ were male, the age ranging from $19-83$ years (mean $\pm \mathrm{SD}=50.66 \pm 12.92$ ). Among 323 aneurysms, 311 had been embolized using Guglielmi detachable coils (GDCs) and 12 giant aneurysm of internal carotid artery (ICA) with presence of good collateral flow had been with detachable balloons.

Clinical presentation: Almost seventy-four percent of patients presented with SAH in the CT scan, $9.2 \%$ had oculomotor palsy, $6.4 \%$ presented with decreased visual acuity and $4.4 \%$ had blindness in the ipsilateral side of the aneurysmal growth. Cerebral aneurysms were detected in $6.4 \%$ of cases presenting with headache as an initial presentation. Clinically, patients presenting with $\mathrm{SAH}$ were classified according to the Hunt and Hess grade; 83 had grade I, 32 had grade II, 39 had grade III, 17 had grade IV and 13 had grade V. Nonparametric K-related statistical analysis showed no statistical significance $(P>0.05)$ between gender and clinical presentation (Table 1). 
Table 1: Comparison between sex and clinical presentation

\begin{tabular}{|c|c|c|c|c|c|c|c|c|c|c|c|}
\hline \multirow[b]{2}{*}{ Sex } & \multirow{2}{*}{$\begin{array}{l}\text { No. of } \\
\text { cases }\end{array}$} & \multirow{2}{*}{$\begin{array}{l}\text { Age } \\
\text { (mean } \\
\pm \\
\text { SD) }\end{array}$} & \multicolumn{9}{|c|}{ Clinical presentation } \\
\hline & & & Hemorrhage & $x^{2}$ & $\begin{array}{l}\text { P- } \\
\text { value }\end{array}$ & Headache & $x^{2}$ & $\begin{array}{l}\text { P- } \\
\text { value }\end{array}$ & $\begin{array}{l}\text { Ocular } \\
\text { symptoms }\end{array}$ & $x^{2}$ & $\begin{array}{l}\mathrm{P} \text { - } \\
\text { value }\end{array}$ \\
\hline Male & 85 & $\begin{array}{c}49.96 \\
\pm \\
14.22\end{array}$ & 65 & \multirow[t]{3}{*}{0.546} & \multirow[t]{3}{*}{0.460} & 6 & \multirow[t]{3}{*}{0.093} & \multirow{3}{*}{0.760} & 14 & \multirow{3}{*}{1.003} & \multirow{3}{*}{0.317} \\
\hline Female & 165 & $\begin{array}{c}50.7 \\
\pm \\
12.44 \\
\end{array}$ & 119 & & & 10 & & & 36 & & \\
\hline Total & 250 & & 184 & & & 16 & & & 50 & & \\
\hline
\end{tabular}

The comparison between aneurysmal location and clinical presentation were statistically insignificant $(P>0.05)$ (Table 2). But comparison between the Hunt and Hess grade and GOS in patients with aneurysmal SAH was statistically significant $(P<0.05)$ (Table 3).

Table 2: Comparison between aneurysmal location and clinical presentation

\begin{tabular}{|c|c|c|c|c|c|c|c|c|c|c|}
\hline \multirow{2}{*}{$\begin{array}{l}\text { Aneurysm } \\
\text { location }\end{array}$} & \multirow{2}{*}{ No. of cases } & \multicolumn{9}{|c|}{ Clinical presentation } \\
\hline & & Hemorrhage & $x^{2}$ & $\begin{array}{l}P \text { - } \\
\text { value }\end{array}$ & Headache & $x^{2}$ & $\begin{array}{l}\text { P- } \\
\text { value }\end{array}$ & $\begin{array}{l}\text { Ocular } \\
\text { symptoms }\end{array}$ & $x^{2}$ & $\begin{array}{l}\mathrm{P} \text { - } \\
\text { value }\end{array}$ \\
\hline $\begin{array}{l}\text { Anterior } \\
\text { circulation }\end{array}$ & 203 & 154 & \multirow{3}{*}{2.844} & \multirow{3}{*}{0.092} & 11 & \multirow{3}{*}{1.736} & \multirow{3}{*}{0.188} & 38 & \multirow{3}{*}{1.107} & \multirow{3}{*}{0.293} \\
\hline $\begin{array}{l}\text { Posterior } \\
\text { circulation }\end{array}$ & 47 & 30 & & & 5 & & & 12 & & \\
\hline Total & 250 & 184 & & & 16 & & & 50 & & \\
\hline
\end{tabular}

Table 3: Comparison between Hunt and Hess grade and Glasgow outcome score

\begin{tabular}{|c|c|c|c|c|c|c|c|c|}
\hline \multirow{2}{*}{$\begin{array}{l}\text { Hunt and Hess } \\
\text { Grade }\end{array}$} & \multirow{2}{*}{ No. of cases } & \multicolumn{7}{|c|}{ Glasgow outcome score (GOS) } \\
\hline & & GOS 5 & GOS 4 & GOS 3 & GOS 2 & GOS 1 & $x^{2}$ & P-value \\
\hline 1 & 83 & 37 & 43 & 3 & 0 & 0 & \multirow{6}{*}{10.958} & \multirow{6}{*}{0.027} \\
\hline 2 & 32 & 12 & 17 & 2 & 1 & 0 & & \\
\hline 3 & 39 & 10 & 22 & 3 & 3 & 1 & & \\
\hline 4 & 17 & 2 & 8 & 2 & 4 & 1 & & \\
\hline 5 & 13 & 1 & 3 & 4 & 2 & 3 & & \\
\hline Total & 184 & 62 & 93 & 14 & 10 & 5 & & \\
\hline
\end{tabular}


Initial angiographic results: A single aneurysm was harbored in 177 (70.8\%) patients and 73 (29.2\%) had multiple aneurysms, of which 69 (94\%) had 2 aneurysms (Figure 1)
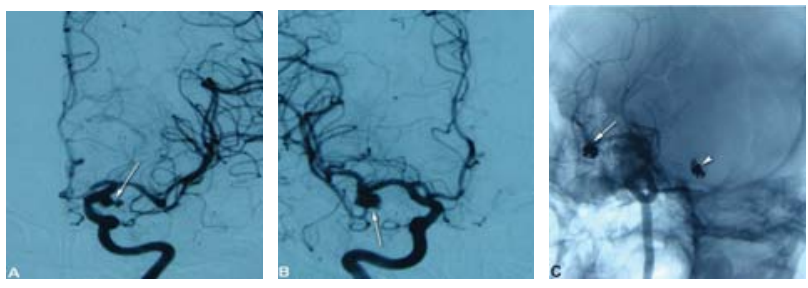

\begin{abstract}
Figure 1. Multiple intracranial aneurysms in a 67-year old lady presented with SAH

A: Bi-lobed right ICA aneurysm (arrow). B: Additional aneurysm in left MCA bifurcation (arrow). C: Total occlusion of MCA (arrow) and ICA aneurysms (arrow head).
\end{abstract}

and $4(5.4 \%)$ harbored 3 aneurysms. The majority of the double aneurysms were in the same side, and in cases with 3 aneurysms, bilateral sides or both anterior and posterior circulations were involved. Seventeen $(9.6 \%)$ had single giant aneurysms: 7 in the cavernous ICA, 6 in the petrous ICA, 2 in the vertebral artery (VA) and 2 in the basilar artery (BA). Two hundred and sixty six $(82.3 \%)$ aneurysms were saccular (Figure 2)
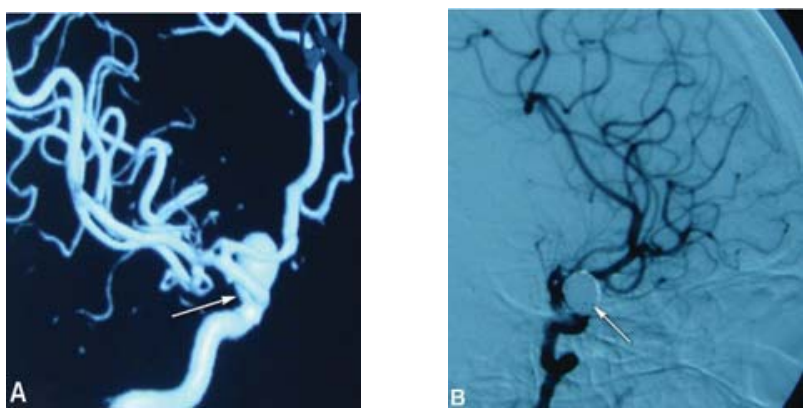

Figure 2. Left Supraclinoid ICA aneurysm in a 23-year old female

A: Supraclinoid ICA saccular aneurysm in 3D rotational DSA (arrow), B: Total obliteration using GDCs (arrow).

31 (9.5\%) were elongated and 26 (8\%) were bilobed aneurysms. The aneurysm size ranged between $35 \mathrm{~mm} \times 24 \mathrm{~mm} \times 18 \mathrm{~mm}-2.5 \mathrm{~mm} \times 2.8 \mathrm{~mm} \times 1.5$ $\mathrm{mm}$. The lesions were confirmed as 54 ICA aneurysms, 21 anterior cerebral artery aneurysms, 136 anterior communicating artery (AcomA) aneurysms (Figure 3)
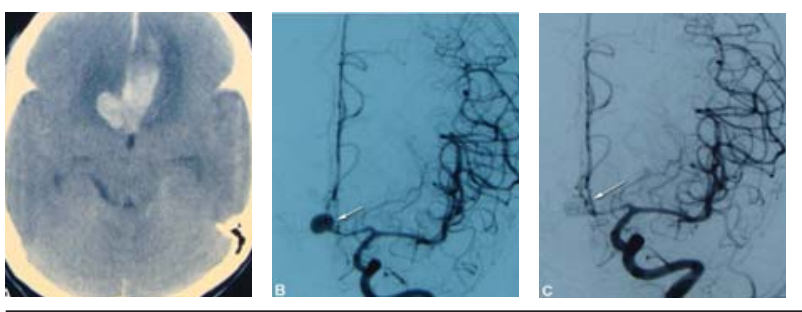

Figure 3. Ruptured AcomA aneurysm in a 59-year old male

A: SAH with focal bleed in fronto-basal region in CT. B: $8 \mathrm{~mm} \times 6 \mathrm{~mm}$ ruptured AcomA aneurysm is detected in left ICA arteriography (arrow) C: Postembolization DSA (arrow)

37 middle cerebral artery (MCA) aneurysms, 28 posterior communicating artery (PcomA) aneurysms (Figure 4)
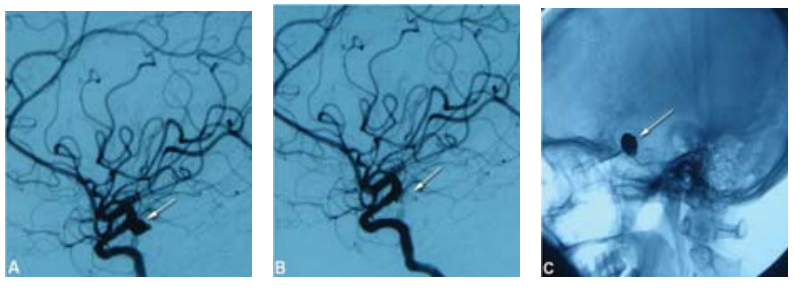

Figure 4. Right PcomA aneurysm in a 54-year female A: ICA arteriography, lateral view shows $10 \mathrm{~mm} x$ $6 \mathrm{~mm}$ aneurysm (arrow) arising from right Pcoma. B: Embolized aneurysm (arrow), C: Dense coil packing (arrow).

13 posterior cerebral artery aneurysms, 12 BA aneurysms, 4 posterior inferior cerebellar artery aneurysms and 18 VA aneurysms (Figure 5).
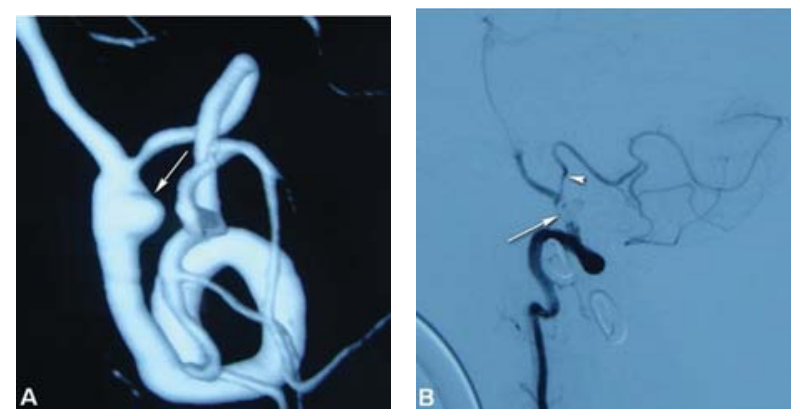

Figure 5. Left VA aneurysm in a 51- year old gentleman

A: $5 \mathrm{~mm} \times 4 \mathrm{~mm}$ wide neck VA aneurysm in 3D rotational DSA (arrow). B: Aneurysm has been embolized along with parent vessel occlusion, preserving the PICA (arrow head). 
Post-procedural angiographic and clinical results:

Among 245 patients, 62 improved to GOS 5, 93 improved to GOS 4, 14 improved to GOS 3 and 10 improved to GOS 2 at the time of discharge. In 2 cases, the power in the affected limbs improved to $3 / 5$ during the $6-12$ months of clinical follow-up. Of 323 aneurysms, total occlusion was seen in 301193 $\%)$ aneurysms, near total occlusion was found in 17 $(5.2 \%)$ and incomplete embolization was detected in $5(1.5 \%)$ cases in the immediate angiography. In the angiographic follow-up, stable occlusion was seen in $91.2 \%$, whereas in $3(1.2 \%)$ cases, the aneurysms recurred, which were re-embolized using additional GDCs. Five patients did not agree to undergo further angiographic investigations and 9 patients were lost for follow-up.

Procedural complications: Four (1.2 \%) aneurysms ruptured during coiling, $0.8 \%$ had transient and permanent ischemic stroke, with $2 \%$ of overall mortality rate for each. Tow died in the third and fifth post-operative day due to severe vasospasm secondary to intra-procedural aneurysmal rupture. Three cases with Hunt and Hess grade $V$ died between 3 - 7 days after coil embolization.

\section{DISCUSSION}

Ruptured intracranial aneurysm is one of the leading neurosurgical emergencies with significant mortality and morbidity rates. Due to the basal locus of the Circle of Willis, craniotomy and clipping of the cerebral aneurysm is more challenging. Endovascular therapy is the best preferred technique done under angiographic suit, producing no damage to the brain parenchyma. It poses minimal discomfort with a better outcome and a speedy postoperative recovery. Lesions are typically found at major vessel bifurcation areas, which correlate with the theory of turbulence in the blood flow mechanism to produce saccular aneurysms in vessel branching locations due to the high hemodynamic stress, stated by Ferguson $\mathrm{GC} .{ }^{4}$ The most common cause of $\mathrm{SAH}$ is ruptured intracranial aneurysms. Almost $74 \%$ of our series presented with aneurysmal SAH detected in CT scan and among them 136 aneurysms were located in the AcomA representing $42.1 \%$ of all the intracranial aneurysms.

Aneurysms located in the AcomA are the most frequent growths of the Circle of Willis. ${ }^{5}$ Aneurysmal SAH (Fisher grade I) was also detected in 12 patients presenting with intractable headache as an initial clinical feature, which might be the initial warning sign of a ruptured aneurysm. In such a situation, immediate embolization is mandatory to prevent early re-bleeding. It has been documented that in this can prevent re-bleeding in the acute phase of
$\mathrm{SAH}^{6} 98 \%$ of the total and near total occluded sacs of aneurysms. Giant aneurysms represent approximately $5 \%$ of all intracranial aneurysms. ${ }^{7}$ Giant lesions often present with mass effect in adjacent structures rather than SAH. In cases with a good collateral flow, the uses of detachable balloons have been primarily in practice for the parent vessel occlusion.8, ${ }^{8}$ We treated 12 giant lesions of ICA with detachable balloons to occlude the parent artery successfully, and in five giant aneurysms with insufficient collateral flow, GDCs were used. The recurrence and recanalization rate is higher after coil embolization of giant aneurysms. ${ }^{10}$ We detected recanalization in $40 \%$ of giant lesions though they were densely packed with $>90 \%$ of occlusion rate in the initial control angiography. The incidence of the third nerve palsy is documented as high as $56 \%$ in association with the growth of PcomA aneurysms. ${ }^{11}$

In our series, $9.2 \%$ of cases presented with oculomotor nerve palsy secondary due to the ipsilateral aneurysmal growth in the PcomA as well as due to the mass effect caused by the giant aneurysms of the cavernous segment of the ICA. Moreover, $6.4 \%$ presented with decreased visual acuity and $4.4 \%$ presented with blindness. Posterior circulation aneurysms account for $10-20 \%$ of all aneurysms found in the circle of Willis and the basilar artery is commonly involved ${ }^{12}$. Since the basilar artery often lacks a good collateral supply and a large number of perforating vessels originating from it contribute to brain stem perfusion, sacrificing the basilar artery is a risky procedure..$^{13}$ So, we embolized all the BA aneurysms by GDCs without affecting the parent vessel and the results were successful. However, in three cases with a wide-neck vertebral artery aneurysm, the parent vessel occlusion was done below the origin of the PICA using GDCs. In patients presenting with multiple aneurysms and $\mathrm{SAH}$, identifying the main source of bleeding is difficult. Only if the bleeding site in the CT correlates with a particular irregular shape among other saccular lesions can the exact source of bleeding be established in DSA.

Craniotomy and clipping of such multiple aneurysms during the same surgical procedure is considered for extreme parenchymal damage ${ }^{14}$, which also justifies the importance of endovascular therapy for obliteration of multiple lesions at the same time. The probability of re-bleeding is very high within the first week of aneurysmal SAH; thus, the timing of the ruptured aneurysm treatment is an essential factor. This is the main reason for considering the endovascular approach for obliteration of the ruptured lesions as soon as possible. Almost $74 \%$ of the patients had ruptured aneurysms and the majority of them were treated in the first five days of the initial hemorrhage. Hunt and 
Hess grade IV and $V$ are usually considered poor clinical gradings in aneurysmal SAH. When patients with poor clinical grades are treated by endovascular means, improvement in the general outcome to GOS IV and V has been previously documented. ${ }^{15,}{ }^{16}$ According to the 2002 views of the International Subarachnoid Aneurysm Trail collaborative group (ISAT), endovascular coil embolization is more likely to offer survival benefits than surgical clipping can. ${ }^{17}$ We detected complete occlusion in $93 \%$ of aneurysms. Recurrence was identified in wide-neck and giant aneurysms, which elucidates the necessity of modified endovascular technique when managing wide neck (> $4 \mathrm{~mm}$ ) aneurysms. Though coils were only used in our series to occlude 323 aneurysms, $82.3 \%$ being saccular aneurysms with a narrow neck $(<4 \mathrm{~mm})$, a neck remnant was detected only in $1.2 \%(3 / 323)$ of the aneurysms.

Nevertheless, the presence of a residual sac or a neck remnant is an additional associated factor for re-bleeding; however, such consequences did not occur in our patients. As compared to the results of surgical clippings of between 5 to $10 \%$ in previous series ${ }^{18,19}$, we had an overall $1.6 \%$ of morbidity and $2 \%$ of mortality rates. The possibility of parent-artery occlusion during coil embolization remains a drawback of the endovascular therapy, but advance technical skill and modified coiling technique has demonstrated significant reduction in the incidence of procedure-related complications. In addition to paying heed the anatomical configuration, it is essential to locate the precise angiographic view for the perfect visualization of the aneurysmal neck while deploying coils, which can minimize the risk of neck-remnants and subsequent re-bleeding. Hence, 3D rotational DSA has a significant function in localizing the aneurysmal neck and its relationship to the parent vessel. Thromboembolic complications usually occur when related to catheter system navigation, whereas coils and balloons are responsible for vessel dissection, vasospasm or thrombus formation. Usually small blood clots or atherosclerotic plaques are scraped off the vessel wall while manipulating the catheter. But the use of anticoagulants during endovascular procedure has dramatically reduced the thromboembolic complications. Though the conventional coil embolization technique is a better option for saccular aneurysms with a narrow neck, however to produce stable occlusion of wide necked or complex shaped aneurysms, modified treatment strategies like stent or balloon assisted coil embolization are obligatory. ${ }^{20,21}$

\section{CONCLUSIONS}

Total aneurysm occlusion was attempted in $93 \%$ of the patients with $1.2 \%$ of them resulting in procedural complications. Angiographic neck recurrence was observed in $1.2 \%$ of cases. Although Hunt and Hess grade $\mathrm{VI}$ and $\mathrm{V}$ are considered to be poor clinical gradings in aneurysmal SAH, in our study series $46.6 \%$ of cases with these grades attained social independence following successful endovascular treatment. 


\section{REFERENCES}

1. Serbinenko FA. Balloon catheterization and occlusion of major cerebral vessels. J Neurosurg. 1974;41(2):125-45.

2. Guglielmi G, Viñuela F, Sepetka I, Macellari V. Electrothrombosis of saccular aneurysms via endovascular approach. Part 1: Electrochemical basis, technique, and experimental results. J Neurosurg. 1991;75(1):1-7.

3. Gonzalez N, Murayama Y, Nien YL, Martin N, Frazee J, Duckwiler $G$ et al. Treatment of unruptured aneurysms with GDCs: clinical experience with 247 aneurysms. AJNR Am J Neuroradiol. 2004;25(4):577-83.

4. Ferguson GG. Physical factors in the initiation, growth, and rupture of human intracranial saccular aneurysms. J Neurosurg. 1972 ;37(6):666-77.

5. Le Roux PD, Elliott JP, Eskridge JM, Cohen W, Winn HR. Risks and benefits of diagnostic angiography after aneurysm surgery: a retrospective analysis of 597 studies. Neurosurgery. 1998;42(6):1248-54.

6. Raymond J, Roy D. Safety and efficacy of endovascular treatment of acutely ruptured aneurysms. Neurosurgery. 1997;41(6):1235-45.

7. Khurana VG, Piepgras DG, Whisnant JP. Ruptured giant intracranial aneurysms. Part I. A study of rebleeding. J Neurosurg. 1998;88(3):425-9.

8. Debrun G, Fox A, Drake C, Peerless S, Girvin J, Ferguson G. Giant unclippable aneurysms: treatment with detachable balloons. AJNR Am J Neuroradiol. 1981;2(2):167-73.

9. Leibowitz R, Do HM, Marcellus ML, Chang SD, Steinberg GK, Marks MP. Parent vessel occlusion for vertebrobasilar fusiform and dissecting aneurysms. AJNR Am J Neuroradiol. 2003;24(5):902-7.

10. Kim SJ, Choi IS. Midterm outcome of partially thrombosed intracranial aneurysms treated with guglielmi detachable coils. Interv Neuroradiol. 2000;6(1):13-25.

11. Yanaka K, Matsumaru Y, Mashiko R, Hyodo A, Sugimoto K, Nose T. Small unruptured cerebral aneurysms presenting with oculomotor nerve palsy. Neurosurgery. 2003;52(3):5537 .
12. Redekop GJ, Durity FA, Woodhurst WB. Managementrelated morbidity in unselected aneurysms of the upper basilar artery. J Neurosurg. 1997;87(6):836-42.

13. Amin-Hanjani S, Ogilvy CS, Buonanno FS, Choi IS, Metz LN. Treatment of dissecting basilar artery aneurysm by flow reversal. Acta Neurochir (Wien). 1997;139(1):44-51.

14. Mizoi K, Suzuki J, Yoshimoto T. Surgical treatment of multiple aneurysms. Review of experience with 372 cases. Acta Neurochir (Wien). 1989;96(1-2):8-14.

15. Bracard S, Lebedinsky A, Anxionnat R, Neto JM, Audibert G, Long $Y$ et al. Endovascular treatment of Hunt and Hess grade IV and V aneuryms. AJNR Am J Neuroradiol. 2002;23(6):953-7.

16. Groden C, Kremer C, Regelsberger J, Hansen HC, Zeumer $H$. Comparison of operative and endovascular treatment of anterior circulation aneurysms in patients in poor grades. Neuroradiology. 2001;43(9):778-83.

17. Molyneux AJ, Kerr RS, Yu LM, Clarke M, Sneade M, Yarnold JA et al. International Subarachnoid Aneurysm Trial (ISAT) Collaborative Group. International subarachnoid aneurysm trial (ISAT) of neurosurgical clipping versus endovascular coiling in 2143 patients with ruptured intracranial aneurysms: a randomised comparison of effects on survival, dependency, seizures, rebleeding, subgroups, and aneurysm occlusion. Lancet. 2005;366(9488):809-17.

18. Drake CG. Progress in cerebrovascular disease. Management of cerebral aneurysm. Stroke. 1981;12(3):273-83.

19. King JT Jr, Berlin JA, Flamm ES. Morbidity and mortality from elective surgery for asymptomatic, unruptured, intracranial aneurysms: a meta-analysis. J Neurosurg. 1994;81(6):837-42.

20. Yoo E, Kim DJ, Kim DI, Lee JW, Suh SH. Bailout Stent Deployment during Coil Embolization of Intracranial Aneurysms. AJNR Am J Neuroradiol. 2009;30(5):1028-34.

21. Fiorella D, Woo HH. Balloon assisted treatment of intracranial aneurysms: the conglomerate coil mass technique. J Neurointerv Surg. 2009;1(2):121-31. 